\title{
PERDAS DE SOLO E ÁGUA E QUALIDADE DO ESCOAMENTO SUPERFICIAL ASSOCIADAS À EROSÃO ENTRE SULCOS EM ÁREA CULTIVADA SOB SEMEADURA DIRETA E SUBMETIDA ÀS ADUBAÇÕES MINERAL E ORGÂNICA ${ }^{(1)}$
}

\author{
Oromar João Bertol ${ }^{(2)}$, Nivaldo Eduardo Rizzi ${ }^{(3)}$, Ildegardis \\ Bertol $^{(4)}$ \& Gláucio Roloff ${ }^{(5)}$
}

\begin{abstract}
RESUMO
Dos métodos de preparo conservacionista do solo, o de semeadura direta é o mais eficaz na redução da perda de solo por erosão hídrica pluvial; entretanto, apresenta comportamento variável no que diz respeito à redução da perda de água. Considerando esses aspectos, realizou-se o presente trabalho com o objetivo de avaliar as perdas de solo e água, a demanda química de oxigênio, a condutividade elétrica e o pH da enxurrada, associados à erosão entre sulcos, sob chuva simulada, em área cultivada sob semeadura direta e submetida às adubações mineral e orgânica. O estudo foi desenvolvido em campo, em outubro de 2003, no município de Marechal Cândido Rondon, na região oeste do Estado do Paraná, sobre um Latossolo Vermelho eutroférrico de textura muito argilosa e declividade de $0,045 \mathrm{~m} \mathrm{~m}^{-1}$. Utilizando microparcelas $(1,0 \times 1,0 \mathrm{~m})$ e simulador de chuva de braços rotativos e com o solo previamente umedecido, aplicaram-se as seguintes intensidades de chuva: $70,0,60,0$ e $120,0 \mathrm{~mm} \mathrm{~h}^{-1}$, cada uma delas com duração de 20 min e espaçadas uma da outra de $30 \mathrm{~min}$. Os tratamentos estudados foram: (a) adubação mineral, constituída de NPK; (b) adubação orgânica, constituída de dejeto líquido de suíno - DLS; e (c) sem adubação ou testemunha - T. As maiores perdas de solo e água no experimento foram observadas no tratamento DLS, independentemente das chuvas simuladas (exceto a perda de solo na última chuva,
\end{abstract}

\footnotetext{
(1) Parte da Tese de Doutorado do primeiro autor apresentada ao Setor de Ciências Agrárias, Centro de Ciências Florestais e da Madeira, Universidade Federal do Paraná - UFPR. Recebido para publicação em dezembro de 2005 e aprovado em março de 2007.

(2) Engenheiro-Agrônomo, Dr. em Engenharia Florestal. EMATER - PR (área de recursos naturais e geoprocessamento). Rua da Bandeira 500, CEP 80035-270 Curitiba (PR). E-mail: oromar@emater.pr.gov.br

(3) Professor do Curso de Engenharia Florestal, Universidade Federal do Paraná - UFPR. Rua dos Funcionários 1540, CEP 80035050 Curitiba (PR). E-mail: niva@ufpr.br

(4) Professor de Uso e Conservação do Solo, Universidade do Estado de Santa Catarina - CAV/UDESC. Caixa Postal 281, CEP 88520-000 Lages (SC). Bolsista do CNPq. E-mail: a2ib@cav.udesc.br

(5) Professor Adjunto, Departamento de Solos e Engenharia Agrícola, UFPR. E-mail: groloff@ufpr.br
} 
que foi a mais elevada), com os tratamentos NPK e $\mathrm{T}$ tendo apresentado resultados semelhantes. Os valores mais elevados de demanda química de oxigênio, condutividade elétrica e pH da enxurrada também foram observados no tratamento DLS, enquanto os mais baixos ocorreram no tratamento $T$ (exceto a demanda química de oxigênio no tratamento NPK, que também foi baixa), independentemente das chuvas simuladas.

Termos de indexação: chuva simulada, erosão entre sulcos, semeadura direta, perda de solo, perda de água, qualidade do escoamento superficial.

\title{
SUMMARY: SOIL AND WATER LOSS AND QUALITY OF SURFACE RUNOFF ASSOCIATED WITH INTERRILL EROSION IN NO-TILLAGE AREA TREATED WITH CHEMICAL AND ORGANIC FERTILIZERS
}

\begin{abstract}
Among conservation tillage methods, no-till has shown to be the most effective in reducing soil losses caused by rainfall erosion, but with considerable data variation regarding water loss. Considering these aspects, this study was carried out with the objective of evaluating soil and water losses, the chemical demand of oxygen (CDO), electrical conductivity, and the $\mathrm{pH}$ of surface runoff, associated with interrill erosion under simulated rainfall. The field study was conducted in October 2003 in Marechal Cândido Rondon county, western Paraná state, Brazil, in an area cultivated under no-till and that received chemical and organic fertilization. The soil is a clayey Oxisol (eutroferric Red Latosol) with $0.045 \mathrm{~m} \mathrm{~m}^{-1}$ slope. On small plots $(1.0 \times 1.0 \mathrm{~m})$ with pre-wetted soil, the following rainfall intensities were applied by a rotating-boom rainfall simulator: 70.0, 60.0 and $120.0 \mathrm{~mm} \mathrm{~h}^{-1}$, during 20 min each, with time intervals of $30 \mathrm{~min}$ in-between. The treatments consisted of: (a) chemical fertilization, with nitrogen, phosphorous, and potassium - NPK; (b) organic fertilization with liquid swine manure-DLS, and (c) no-fertilization (control treatment) $T$. The highest soil and water losses in the experiment were observed in the DLS treatment, regardless of the simulated rains (except soil loss in the last rain, which reached the highest value in the study); the results of NPK and control T treatments were similar. The highest values of chemical oxygen demand, electrical conductivity and $\mathrm{pH}$ of surface runoff were also observed in the DLS treatment, while the lowest values occurred in the Treatment (except the chemical oxygen demand in the NPK treatment, which was also low), regardless of the simulated rains.
\end{abstract}

Index terms: simulated rainfall, interrill erosion, no-till, soil loss, water loss, quality of surface runoff

\section{INTRODUÇÃO}

A erosão hídrica do solo pode se manifestar de modo distinto, de acordo com o local onde ela ocorre; por se constituir no mais importante meio de transporte dos nutrientes das culturas das lavouras para os mananciais de água, é o principal agente de poluição difusa. O entendimento do processo de erosão hídrica do solo é facilitado separando-a em erosão entre sulcos e erosão em sulcos, com base nas características distintas do seu fluxo superficial, as quais controlam a mecânica do processo erosivo em cada uma dessas formas (Meyer et al., 1975).

A erosão entre sulcos usualmente é mais seletiva do que a erosão em sulcos, uma vez que nela ocorre o transporte das partículas de menor diâmetro. Essas partículas menores são desprendidas dos agregados de solo, principalmente pelo impacto das gotas da chuva, sendo as primeiras a serem transportadas, caracterizando dessa forma a seletividade do processo erosivo. Assim, embora a quantidade de solo perdida na erosão entre sulcos seja menor do que na erosão em sulcos, a maior concentração de elementos minerais nos sedimentos finos indica que a primeira não deve ser desprezada (Foster, 1982).

Isoladamente, a cobertura do solo por resíduos vegetais é o fator mais importante na dissipação da energia de impacto das gotas da chuva na superfície do solo (Foster, 1982), visto que ela pode evitar a desagregação de suas partículas. Além disso, os 
resíduos vegetais em contato direto com a superfície do solo são muito eficazes na redução da carga de sedimentos no escoamento superficial ou enxurrada, pois, sob tal forma, eles formam uma intrincada rede, filtrando os sedimentos em suspensão na enxurrada quando esta passa por entre suas peças (Foster, 1982). $\mathrm{O}$ efeito protetor da cobertura do solo por resíduos vegetais é melhor evidenciado nos períodos em que o solo é mobilizado, mesmo que em pouca extensão, como ocorre na operação de semeadura denominada sem preparo do solo ou semeadura direta. Com cobertura parcial, a superfície do solo fica menos protegida da ação conjunta das gotas da chuva e da enxurrada a ela associada, e, quando isso coincide com períodos de chuva de elevada erosividade, os riscos de erosão aumentam.

A técnica de semeadura direta também se caracteriza por manter a maior parte da superfície do solo consolidada, protegida por resíduos vegetais e com baixa rugosidade superficial (Cogo, 1981). Por essa razão, ela apresenta maior eficácia no controle da perda de solo do que no controle da perda de água (Cogo et al., 2003). A menor eficácia da semeadura direta no controle da perda de água, comparada à perda de solo, deve-se ao fato de que, independentemente do tipo de preparo utilizado, o solo apresenta capacidade finita de infiltração de água, a partir da qual a taxa de enxurrada tende a se igualar nos diferentes tipos de preparo. Por outro lado, a técnica de semeadura direta tem proporcionado acúmulo de nutrientes na superfície do solo (Schick et al., 2000), pela não-inversão da sua camada arável, o que favorece a concentração de nutrientes na enxurrada (Schick et al., 2000). A erosão hídrica, por ser seletiva, preferencialmente transporta os sedimentos mais finos, de menor diâmetro e de baixa densidade, constituídos sobretudo de colóides minerais e orgânicos e normalmente enriquecidos de elementos minerais (Bertol et al., 2007).

Os sedimentos transportados na enxurrada também se diferenciam quanto à textura, cuja variação influencia a velocidade de sedimentação das partículas no fluxo, conforme a lei de Stokes (Tundisi, 2001). As partículas de menor tamanho e de baixa densidade, como a argila e a matéria orgânica, apresentam movimento errático quando em suspensão em água, o que dificulta sua decantação. Assim, esses sedimentos permanecem suspensos na enxurrada por maior período de tempo, sendo mais expostos às reações de sorção/dessorção na massa de água do que os sedimentos de maior tamanho, os quais decantam mais rapidamente. Dessa forma, grandes quantidades de sedimentos em suspensão, especialmente os coloidais, favorecem o transporte de nutrientes por erosão hídrica (Koski-Vähälä \& Hartikainen, 2001). Com isso, os ambientes situados fora da área de origem da erosão são degradados pelo aumento da turbidez e da eutrofização das águas. Isso acontece porque os sedimentos finos apresentam alta atividade química e, em geral, são altamente enriquecidos de nutrientes (Bertol et al., 2007).
Em face do exposto, realizou-se o presente trabalho com o objetivo de avaliar as perdas de solo, água e nutrientes das culturas na erosão entre sulcos, em solo cultivado sob a técnica de semeadura direta e submetido às adubações mineral e orgânica, com o intuito de obter informações básicas que possam fundamentar a necessidade de se controlar a erosão hídrica pluvial e a enxurrada superficial a ela associada e, conseqüentemente, reduzir a poluição difusa causada por tais agentes.

\section{MATERIAL E MÉTODOS}

As ações experimentais de campo foram desenvolvidas em outubro de 2003 e concentraram-se na região oeste do Estado do Paraná, no município de Marechal Cândido Rondon. Aárea experimental situase entre as coordenadas UTM 194.290 e 7.283.460. Segundo a classificação de Köppen, o clima da região é do tipo Cfa - subtropical úmido, sem estação seca (Brasil, 1981). O solo da área experimental (Quadro 1) é classificado como Latossolo Vermelho eutroférrico (Embrapa, 1999), possuindo textura muito argilosa e declividade média de $0,045 \mathrm{~m} \mathrm{~m}^{-1}$, e com os seguintes valores de características físicas na camada de 0 a $20 \mathrm{~cm}: 1,29 \mathrm{~kg} \mathrm{dm}^{-3}$ de densidade do solo, $2,74 \mathrm{~kg} \mathrm{dm}^{-3}$ de densidade de partículas, $0,41 \mathrm{dm}^{3} \mathrm{dm}^{-3} \mathrm{de}$ microporos, $0,11 \mathrm{dm}^{3} \mathrm{dm}^{-3}$ de macroporos e $0,52 \mathrm{dm}^{3} \mathrm{dm}^{-3}$ de porosidade total. A densidade do solo e a de partículas foram determinadas, respectivamente, pelos métodos do anel e do balão volumétrico, conforme Embrapa (1997).

As características de solo mostradas no quadro 1 foram determinadas pelos seguintes métodos: granulometria, por densitometria, conforme Embrapa (1997); C orgânico, por colorimetria; P e K, pelo método de Mehlich; Ca, Mg e Al, por extração com $\mathrm{KCl} 1 \mathrm{~N}$; e $\mathrm{pH}$ em $\mathrm{CaCl}_{2}$ 0,01M, todos conforme consta em Pavan et al. (1992); hematita, por extração com oxalato de amônio 0,2 $\mathrm{mol} \mathrm{L}^{-1}$ (McKeague, 1978) e com DCB (Mehra \& Jackson, 1960); e caulinita, conforme Melo et al. (2001).

Nos últimos cinco anos (1999 a 2003), o solo foi cultivado sob a técnica de semeadura direta, com a seguinte rotação de culturas: soja (Glycine max), aveia-preta (Avena strigosa), milho (Zea mays), triticale (X. triticosecale), milho (Zea mays) e trigo (Triticum aestivum). Por ocasião da realização do estudo, a superfície do solo na área experimental continha resteva composta predominantemente por resíduos culturais de trigo e milho.

Antes da implantação dos tratamentos do estudo, foi realizada a operação de semeadura direta, com máquina semeadora-adubadora provida de sulcadores tipo cinzel, distanciados entre si de 0,40 m. Esses sulcadores produziram sulcos no solo com largura e profundidade aproximadas de, respectivamente, 0,05 
Quadro 1. Características físicas, químicas e mineralógicas do solo utilizado no estudo (Latossolo Vermelho eutroférrico)

\begin{tabular}{|c|c|c|c|c|c|c|c|c|c|c|c|c|c|}
\hline \multirow{2}{*}{ Camada avaliada } & \multicolumn{13}{|c|}{ Característica de solo } \\
\hline & Ag & Af & $\mathbf{S i}$ & Ar & $\mathrm{CO}$ & $\mathbf{P}$ & $\mathbf{K}$ & $\mathbf{C a}$ & Mg & Al & pH & $\mathrm{Ct}$ & $\mathrm{He}$ \\
\hline $\mathrm{cm}$ & $\underline{-}$ & 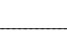 & $\mathrm{g} \mathrm{kg}^{-1}$ & 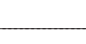 & . & $\mathrm{mg} \mathrm{kg}^{-1}$ & 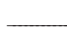 & $-\mathrm{mmc}$ & $\mathrm{kg}^{-1}$ & - & $1: 1$ & 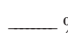 & $\underline{-}$ \\
\hline $0-2,5$ & 39,1 & 58,8 & 219,2 & 682,9 & 21,4 & 65,3 & 8,15 & 68,3 & 36,8 & 0,0 & 6,25 & 68,1 & 21,0 \\
\hline $2,5-20$ & 37,8 & 43,1 & 184,4 & 734,7 & 11,9 & 52,5 & 2,75 & 41,5 & 20,5 & 0,0 & 5,33 & 58,3 & 21,6 \\
\hline
\end{tabular}

$\mathrm{Ag}=$ areia grossa $; \mathrm{Af}=$ areia fina $; \mathrm{Si}=$ silte $; \mathrm{Ar}=$ argila $; \mathrm{CO}=$ carbono orgânico; $\mathrm{Ct}=$ caulinita $; \mathrm{He}=$ hematita.

e $0,08 \mathrm{~m}$, os quais, no entanto, foram obliterados pela chuva de umedecimento realizada. Esse fato promoveu, no interior das unidades experimentais ou microparcelas, uma condição de superfície propícia à ocorrência da erosão entre sulcos. A operação de semeadura foi realizada no sentido da maior declividade do terreno, do mesmo modo como usualmente fazem os agricultores em lavouras conduzidas sob a técnica de semeadura direta e sem terraceamento, e também por representar a condição crítica para ocorrência da enxurrada, bem como de transporte de solo no processo de erosão hídrica pluvial.

As unidades experimentais, com dimensões de 1,0 x 1,0 m cada uma, foram delimitadas com chapas metálicas cravadas no solo. Na parte frontal (extremidade inferior) de cada parcela, foi instalada uma calha coletora, autolimpante, para recolher a enxurrada superficial proveniente do interior desta. Para coleta de enxurrada, foi aberta uma pequena trincheira, em frente à calha, com dimensões e profundidade suficientes para comportar um recipiente com capacidade de armazenamento de 25,0 L, o qual foi acoplado à calha coletora de enxurrada.

Os tratamentos estudados, com quatro repetições, foram: (a) adubação mineral, com NPK, aplicada na superfície do solo, dentro das parcelas, na quantidade de $20 \mathrm{~g} /$ parcela, correspondendo a $200 \mathrm{~kg} \mathrm{ha}^{-1}$ (tratamento NPK); (b) adubação orgânica, com dejeto líquido de suíno, aplicada na superfície do solo, dentro das parcelas, na quantidade de $6,0 \mathrm{~L} /$ parcela, correspondendo a $60 \mathrm{~m}^{3} \mathrm{ha}^{-1}$ (tratamento DLS); e (c) sem adubação ou testemunha (tratamento $\mathrm{T}$ ).

Dezesseis horas após a aplicação das adubações supracitadas, foram iniciadas as chuvas simuladas, com o uso do aparelho simulador de chuva de braços rotativos (Swanson, 1965). Inicialmente, foi aplicada uma chuva de umedecimento, com intensidade média de $57,0 \mathrm{~mm} \mathrm{~h}^{-1}$ e duração de $40 \mathrm{~min}$, tendo sido interrompida logo ao iniciar o empoçamento de água no microrrelevo da superfície do solo, antes de desencadear a enxurrada. Trinta minutos após o término dessa chuva, foi aplicada uma série de três chuvas simuladas (chuvas principais do estudo), com a finalidade de produzir enxurrada, cada uma delas com duração de 20 min e espaçadas uma da outra de $30 \mathrm{~min}$, sendo a primeira na intensidade constante de $70,0 \mathrm{~mm} \mathrm{~h}^{-1}$ (C1), a segunda de 60,0 $\mathrm{mm} \mathrm{h}^{-1}$ (C2) e a terceira de $120,0 \mathrm{~mm} \mathrm{~h}^{-1}$ (C3). As lâminas de água aplicadas na chuva de umedecimento, chuva principal 1 (C1), chuva principal 2 (C2) e chuva principal 3 (C3), medidas por meio de pluviômetros colocados sob a área de projeção de água do aparelho simulador de chuva, foram de, respectivamente, 38,0, 23,0, 20,0 e 40,0 mm.

Após a aplicação das chuvas principais (C1, C2 e C3), os recipientes com a enxurrada de cada chuva, em cada parcela, foram retirados das trincheiras, pesados e conduzidos ao laboratório, para sua quantificação. Imediatamente após a chegada dos recipientes ao laboratório, foram feitas amostragens da enxurrada para as seguintes determinações: sedimentos totais na enxurrada, em alíquota de $500 \mathrm{~mL} ; \mathrm{pH}$ e condutividade elétrica (CE) da enxurrada, em alíquota de $200 \mathrm{~mL}$; e demanda química de oxigênio (DQO) da enxurrada, em alíquota de $500 \mathrm{~mL}$. O restante da enxurrada foi mantido nos respectivos recipientes, em estado de repouso, por $24 \mathrm{~h}$, para permitir que os sedimentos grossos (decantáveis) se separassem dos finos (neste trabalho, estes últimos são denominados de sedimentos suspensos na enxurrada). Após 24 h, foi feita nova amostragem da enxurrada nos recipientes, em alíquota de $500 \mathrm{~mL}$, para determinar a condutividade elétrica da enxurrada e os sedimentos finos suspensos nesta. Assim, a enxurrada foi avaliada sob duas condições: enxurrada contendo os sedimentos totais, compreendendo a soma dos sedimentos que decantaram num período de $24 \mathrm{~h}$ (grossos) e os sedimentos que ficaram suspensos nesse período (finos); e enxurrada contendo apenas os sedimentos suspensos (finos), denominada de sobrenadante da enxurrada, no qual os sedimentos permaneceram suspensos após o período de repouso de $24 \mathrm{~h}$.

Após determinados o pH em água (1:1) e a condutividade elétrica da enxurrada, as amostras foram centrifugadas por $10 \mathrm{~min}$, a 4.500 RPM. O sobrenadante das amostras centrifugadas foi filtrado, em filtro de 0,45 $\mu \mathrm{m}$, e nessas amostras determinouse a condutividade elétrica da água filtrada. A massa de sedimentos totais e a daqueles suspensos na 
enxurrada foram determinadas da seguinte forma: secagem prévia dos sedimentos em estufa, a $65^{\circ} \mathrm{C}$, seguida da sua secagem final, também em estufa, porém agora a $105^{\circ} \mathrm{C}$, por $24 \mathrm{~h}$, tendo a massa de sedimentos totais e de sedimentos suspensos sido obtida por pesagem. $\mathrm{O}$ volume de água escoado na forma de enxurrada foi determinado subtraindo-se o volume de sedimentos totais perdido durante as chuvas do volume total de enxurrada, assumindo-se a unidade $\left(1,0 \mathrm{~g} \mathrm{dm}^{-3}\right)$ para a densidade da água e $2,74 \mathrm{~kg} \mathrm{dm}^{-3}$ para a densidade de partículas dos sedimentos. As perdas de sedimentos totais, sedimentos suspensos na enxurrada e água na forma de enxurrada, determinadas com base na área de cada unidade experimental ou microparcela, foram extrapoladas para a unidade de área de hectare. Com os valores de volume de água, massa de sedimentos totais e massa de sedimentos suspensos na enxurrada, foram obtidas as concentrações de sedimentos totais e de sedimentos suspensos na enxurrada. As amostras usadas para determinar a demanda química de oxigênio da enxurrada foram acidificadas com $1,0 \mathrm{~mL}$ de $\mathrm{H}_{2} \mathrm{SO}_{4}$ puro e armazenadas, para posterior análise.

A cobertura do solo por resíduos vegetais foi determinada pelo método fotográfico, nas seguintes etapas de condução do experimento: antes da operação de semeadura (cobertura inicial do solo), após a operação de semeadura e após a aplicação da série de chuvas simuladas.

O delineamento experimental utilizado foi o inteiramente aleatorizado, com distribuição fatorial dos tratamentos, ou seja, tratamento DLS, tratamento NPK e tratamento T versus chuva 1 (C1), chuva 2 (C2) e chuva 3 (C3). As comparações múltiplas foram realizadas por contrastes ortogonais do teste $\mathrm{F}$, conforme Steel \& Torrie (1980).

\section{RESULTADOS E DISCUSSÃO}

Observando os resultados no quadro 2, verifica-se que a superfície do solo encontrava-se quase que totalmente coberta (92\%) pelos resíduos vegetais que existiam na área experimental antes do início do experimento. A operação de semeadura direta neste estudo reduziu a cobertura inicial do solo em 22 pontos percentuais, em concordância com Bertol et al. (1997). Esses autores, estudando o efeito de diferentes mecanismos sulcadores de máquinas semeadorasadubadoras, constataram que todos os tipos de sulcador diminuíram substancialmente a cobertura do solo. Esse resultado pode ser explicado pela ação que o sulcador tipo cinzel desenvolve no solo, ou seja, ele age frontalmente durante seu deslocamento, rompe o solo e, ao mesmo tempo, afasta para os lados os resíduos da linha de semeadura (Bertol et al., 1997). Isso demonstra que, na técnica de semeadura direta, a operação de semeadura pode criar uma condição crítica para as perdas de água e solo por erosão hídrica, dependendo da presença e tipo de sulcador acoplado à máquina semeadora.

Quanto à perda de água da chuva na forma de enxurrada, verifica-se no quadro 3 que os tratamentos estudados a influenciaram nas duas primeiras chuvas principais (C1 e C2). Nestas chuvas, a altura da lâmina de enxurrada no tratamento com dejeto líquido de suíno (DLS) foi aproximadamente duas vezes maior do que nos outros dois. Esse comportamento dos dados concorda com o também verificado por Haynes \& Swift (1990). A maior perda de água neste tratamento, nas duas primeiras chuvas em questão (C1 e C2), em relação aos demais, é explicada do modo a seguir. O período de tempo transcorrido entre a aplicação do dejeto líquido de suíno na superfície do solo e a aplicação da primeira chuva principal (C1) foi de $16 \mathrm{~h}$, tempo este provavelmente suficiente para que pelo menos parte dos compostos orgânicos sólidos presentes no referido dejeto ocupasse os poros do solo, especialmente os macroporos, obstruindo-os. Além disso, o DLS aplicado na superfície do solo provavelmente provocou efeito hidrofóbico neste, conforme referido por Haynes \& Swift (1990). Esse fenômeno promove a repelência da água, dificultando, portanto, a infiltração desta no solo. Assim, o provável efeito hidrofóbico do DLS alterou o comportamento da hidrologia de superfície neste tratamento, diminuindo a infiltração de água, enquanto a obstrução parcial dos macroporos alterou a condutividade hidráulica do solo.

Quadro 2. Contraste de médias do efeito da operação de semeadura e da série de chuvas simuladas aplicadas sobre a cobertura do solo por resíduos vegetais

\begin{tabular}{|c|c|c|c|c|}
\hline \multicolumn{3}{|c|}{ Cobertura do solo } & \multicolumn{2}{|c|}{ Contraste } \\
\hline CI & CAS & CAC & CI vs CAS, CAC & CAS vs CAC \\
\hline \multicolumn{3}{|c|}{ - $\%$} & \multicolumn{2}{|c|}{$\operatorname{Pr}>\mathrm{F}$} \\
\hline $91,8 \pm 1,3$ & $70,5 \pm 2,1$ & $67,5 \pm 1,8$ & $<0,0001$ & 0,25 \\
\hline
\end{tabular}

Pr > F = p-valor da estatística F para contrastes ortogonais; CI = cobertura superficial inicial do solo; CAS = cobertura superficial do solo após a operação de semeadura; CAC = cobertura superficial do solo após a aplicação da série de chuvas simuladas. 
A maior altura da lâmina de enxurrada observada no tratamento DLS, em relação aos outros dois (Quadro 3), pode significar que a influência do dejeto líquido de suíno na formação de enxurrada é maior nas chuvas que ocorrem logo após a sua aplicação no solo, uma vez que a perda de água mais elevada neste tratamento foi observada nas duas primeiras chuvas principais ( $\mathrm{C} 1$ e $\mathrm{C} 2)$, diminuindo na última (C3). No entanto, é necessário considerar que, na região onde o trabalho foi desenvolvido, este tipo de adubo (DLS) é distribuído, na maior parte das vezes, na época da colheita das culturas de inverno, antes da semeadura das culturas de verão. Por outro lado, na referida região essa época do ano coincide com a incidência de chuvas de alta erosividade, geralmente sobre solos parcialmente descobertos e parcialmente mobilizados pelas operações de semeadura. Em decorrência disso, e considerando a magnitude da perda de água observada neste trabalho, a qual, para o maior valor, correspondeu a $125.000 \mathrm{~L} \mathrm{ha}^{-1}$ (chuva C3, no tratamento DLS), pode-se inferir que os danos ambientais ocasionados por tal perda podem ser expressivos, particularmente nas bacias hidrográficas constituídas de rampas longas e, ou, inclinadas e sem nenhum sistema de terraceamento.

No que diz respeito às intensidades de chuva, elas influenciaram a perda de água em todos os tratamentos estudados (Quadro 3). Esse comportamento é mais evidente quando se analisam conjuntamente as intensidades de chuva e a perda de água. Assim, a chuva C3 (intensidade de 120,0 $\mathrm{mm} \mathrm{h}^{-1}$ ) foi 1,6 vez mais intensa do que a chuva $\mathrm{C} 1\left(70,0 \mathrm{~mm} \mathrm{~h}^{-1}\right)$, enquanto a altura da lâmina de água perdida na chuva C3 foi de 2,9 a 4,2 vezes maior do que a altura da lâmina de água perdida na chuva $\mathrm{C} 1$, dependendo do tratamento. A maior perda de água na forma de enxurrada na chuva de maior intensidade pode ser explicada pelo fato de que chuvas intensas produzem grande volume de água em curto espaço de tempo, no qual a taxa de infiltração de água no solo é excedida, particularmente quando tais chuvas incidem sobre o solo já úmido. Isso resulta em sobrecarga hidráulica, desencadeando rapidamente o fluxo superficial. A perda de água observada neste trabalho pode ser considerada baixa em todos os tratamentos estudados, tendo em vista que, mesmo na situação de maior perda

Quadro 3. Contraste de médias das perdas de água (lâmina de enxurrada), sedimentos totais e sedimentos suspensos na enxurrada, nas três chuvas simuladas (C1, C2 e C3), nos tratamentos com adubação orgânica (dejeto líquido de suíno - DLS), adubação mineral (NPK) e sem adubo ou testemunha (T)

\begin{tabular}{|c|c|c|c|c|c|}
\hline \multirow{2}{*}{ Chuva } & \multicolumn{3}{|c|}{ Tratamento } & \multicolumn{2}{|c|}{ Contraste } \\
\hline & DLS & NPK & $\mathbf{T}$ & T vs DLS, NPK & DLS vs NPK \\
\hline & \multicolumn{3}{|c|}{ Lâmina de enxurrada (mm) } & \multicolumn{2}{|c|}{$\operatorname{Pr}>\mathrm{F}$} \\
\hline $\mathrm{C} 1\left(70 \mathrm{~mm} \mathrm{~h}^{-1} ; 23 \mathrm{~mm}\right)$ & $4,3 \pm 0,28$ & $2,1 \pm 0,06$ & $2,2 \pm 0,07$ & 0,0013 & $<0,0001$ \\
\hline $\mathrm{C} 2\left(60 \mathrm{~mm} \mathrm{~h}^{-1} ; 20 \mathrm{~mm}\right)$ & $2,3 \pm 0,10$ & $1,2 \pm 0,07$ & $1,2 \pm 0,05$ & 0,0004 & $<0,0001$ \\
\hline $\mathrm{C} 3\left(120 \mathrm{~mm} \mathrm{~h}^{-1} ; 40 \mathrm{~mm}\right)$ & $12,5 \pm 1,00$ & $8,9 \pm 1,50$ & $9,1 \pm 1,29$ & 0,3450 & 0,0787 \\
\hline Contraste & & & $\operatorname{Pr}>\mathrm{F}$ & & \\
\hline $\mathrm{C} 1$ vs $\mathrm{C} 2, \mathrm{C} 3$ & 0,002 & 0,0221 & 0,0099 & & \\
\hline \multirow[t]{2}{*}{$\mathrm{C} 2 \mathrm{vs} \mathrm{h} 3$} & $<0,0001$ & 0,0001 & $<0,0001$ & & \\
\hline & \multicolumn{5}{|c|}{ Sedimentos totais na enxurrada $\left(\mathrm{kg} \mathrm{ha}^{-1}\right)$} \\
\hline $\mathrm{C} 1\left(70 \mathrm{~mm} \mathrm{~h}^{-1} ; 23 \mathrm{~mm}\right)$ & $120,9 \pm 9,5$ & $56,8 \pm 6,7$ & $72,2 \pm 9,9$ & 0,1570 & 0,0006 \\
\hline $\mathrm{C} 2\left(60 \mathrm{~mm} \mathrm{~h}^{-1} ; 20 \mathrm{~mm}\right)$ & $54,1 \pm 4,6$ & $27,9 \pm 2,3$ & $34,6 \pm 2,8$ & 0,1604 & 0,0004 \\
\hline C3 $\left(120 \mathrm{~mm} \mathrm{~h}^{-1} ; 40 \mathrm{~mm}\right)$ & $757,0 \pm 89,8$ & $548,4 \pm 70,6$ & $425,1 \pm 57,3$ & 0,0328 & 0,0766 \\
\hline Contraste & & & $\operatorname{Pr}>\mathrm{F}$ & & \\
\hline $\mathrm{C} 1$ vs $\mathrm{C} 2, \mathrm{C} 3$ & 0,0016 & 0,0013 & 0,004 & & \\
\hline \multirow[t]{2}{*}{ C2 vs h3 } & $<0,0001$ & $<0,0001$ & $<0,0001$ & & \\
\hline & \multicolumn{5}{|c|}{ Sedimentos suspensos na enxurrada $\left(\mathrm{kg} \mathrm{ha}^{-1}\right)$} \\
\hline $\mathrm{C} 1\left(70 \mathrm{~mm} \mathrm{~h}^{-1} ; 23 \mathrm{~mm}\right)$ & $43,5 \pm 1,5$ & $21,9 \pm 1,2$ & $21,0 \pm 1,3$ & $<0,0001$ & $<0,0001$ \\
\hline $\mathrm{C} 2\left(60 \mathrm{~mm} \mathrm{~h}^{-1} ; 20 \mathrm{~mm}\right)$ & nd & nd & nd & & \\
\hline C3 $\left(120 \mathrm{~mm} \mathrm{~h}^{-1} ; 40 \mathrm{~mm}\right)$ & $103,3 \pm 7,6$ & $91,5 \pm 13,0$ & $94,6 \pm 11,0$ & 0,8550 & 0,4602 \\
\hline Contraste & \multicolumn{5}{|c|}{$\operatorname{Pr}>\mathrm{F}$} \\
\hline $\mathrm{C} 2$ vs $\mathrm{C} 3$ & $<0,0001$ & 0,0018 & 0,0005 & & \\
\hline
\end{tabular}

Pr $>$ F $=$ p-valor da estatística $\mathrm{F}$ para contrastes ortogonais; $\mathrm{nd}=$ não determinado. 
(chuva C3, no tratamento DLS), ela correspondeu a $32 \%$ do volume total de chuva. Mesmo baixa, essa perda de água pode ter significado ambiental desastroso, quando relacionada à área de dada bacia hidrográfica, uma vez que a enxurrada é o principal veículo de transporte de nutrientes e de sedimentos para os mananciais de água, constituindo-se, assim, no principal fator de poluição não-pontual ou difusa. Portanto, considerando as condições sob as quais este trabalho foi desenvolvido, os resultados de perda de água na forma de enxurrada nele observados evidenciam a necessidade de se controlar a erosão hídrica do solo nas lavouras conduzidas sob a técnica de semeadura direta.

A perda de sedimentos totais, transportados na enxurrada, foi influenciada pelo tipo de adubação nas duas primeiras chuvas principais (C1 e C2 - Quadro 3). Esse resultado seguiu a mesma tendência da perda de água, demonstrando a influência da altura da lâmina de enxurrada no transporte de sedimentos. Assim, o maior volume de enxurrada gerado pelas duas primeiras chuvas aplicadas sobre o dejeto líquido de suíno (DLS) transportou maior quantidade de sedimentos totais neste tratamento do que nos demais. $\mathrm{O}$ efeito do volume de enxurrada no transporte de sedimentos totais é confirmado quando se analisa a concentração de sedimentos totais na enxurrada (Quadro 4), visto que essa variável não sofreu influência do tipo de adubação. Bertol et al. (2004), avaliando a erosão hídrica em diferentes sistemas de manejo do solo, também observaram que a perda de solo seguiu a mesma tendência da perda de água, especialmente nos tratamentos com semeadura direta.

A quantidade de sedimentos totais transportada na enxurrada foi distinta nas diferentes chuvas, seguindo a mesma tendência da perda de água. No entanto, comparando as chuvas $\mathrm{C} 1$ e $\mathrm{C} 3$, por exemplo, verifica-se que a relação entre intensidade da chuva e perda de água variou de 2,9 a 4,2 vezes nos diferentes tratamentos, enquanto a relação entre intensidade da chuva e perda de solo variou de 5,9 a 9,7 vezes. Isso significa que o efeito da intensidade da chuva na perda de água e de solo foi diferenciado, o que é confirmado pela concentração de sedimentos totais na enxurrada, em que, na chuva C3, o valor desta variável foi em torno de duas vezes maior do que nas chuvas $\mathrm{C} 1$ e $\mathrm{C} 2$. Esse comportamento pode ser explicado pelas razões a seguir expostas. As duas primeiras chuvas (C1 e C2), de menor intensidade, desagregaram e transportaram partículas de solo por impacto de suas gotas, já que a forma de erosão predominante nestas foi a entre sulcos. Essas duas chuvas propiciaram menor volume de enxurrada e, por isso, não tiveram energia suficiente para transportar todo o solo desagregado. Já a última chuva (C3), de maior intensidade, foi aplicada sobre o solo já umedecido pelas duas primeiras chuvas principais (C1 e C2). Essa condição diminuiu a estabilidade dos agregados de solo, conforme também constatado por Reichert \& Cabeda (1992). Esse fato, aliado à maior desagregação de solo na chuva de maior intensidade (C3), produziu grande quantidade de sedimentos, pois, na erosão entre sulcos, a erosividade da chuva é dependente da sua intensidade e do seu volume (Foster, 1982). Além disso, as duas primeiras chuvas principais (C1 e C2) saturaram o solo, o que favoreceu a formação de enxurrada na última chuva (C3), e enxurradas de maior volume possuem maior capacidade de transporte de sedimentos, em razão de sua maior energia, em relação às enxurradas de menor volume.

Vários trabalhos têm evidenciado a baixa perda de solo sob semeadura direta, comparada à observada no preparo convencional do solo (Cogo, 1981; Bertol et al., 2004). A perda de sedimentos totais na enxurrada observada neste estudo (Quadro 3), convertida para a área de um $(1,0)$ hectare, equivaleu a $28 \mathrm{~kg}$ para o menor valor registrado (chuva $\mathrm{C} 2$, no tratamento NPK) e a $757 \mathrm{~kg}$ para o maior valor (chuva C3, no tratamento DLS). É importante ainda levar em conta que as parcelas experimentais utilizadas neste estudo apresentavam baixa declividade $\left(0,045 \mathrm{~m} \mathrm{~m}^{-1}\right)$ e que a forma de erosão predominante foi a entre sulcos, ocasionada quase que exclusivamente pelo salpico das gotas de chuva, podendo-se, portanto, considerar que não houve escoamento concentrado, mas apenas laminar ou na forma delgada. Com isso, pode-se considerar que a perda de sedimentos totais na enxurrada foi substancial, principalmente levando-se em conta os valores acumulados nas três chuvas principais $(\mathrm{C} 1+\mathrm{C} 2+\mathrm{C} 3)$. Isso ocorreu pelo fato de que parte da superfície do solo ficou descoberta, em virtude de a operação de semeadura ter sido efetuada com máquina provida de sulcadores, e também em razão de a referida operação ter sido executada no sentido da pendente do terreno.

A quantidade de sedimentos totais perdida por erosão hídrica na técnica de semeadura direta utilizada neste estudo foi menor do que a normalmente verificada no método convencional de preparo do solo. No entanto, pode-se considerar que os efeitos ambientais fora do local de origem da erosão, decorrentes da deposição de sedimentos, são importantes. A erosão entre sulcos usualmente é mais seletiva do que a erosão em sulcos (Foster, 1982) e, desse modo, os sedimentos transportados nesta são predominantemente constituídos de colóides minerais e orgânicos. Essas partículas e compostos são muito ativos quimicamente e, por isso, em geral são enriquecidos de elementos minerais adsorvidos. Por isso, tais frações constituem causa da eutrofização dos mananciais de água onde elas se depositam (Mcdowell \& Sharpley, 2001; Sharpley et al., 2001), principalmente porque parte dos elementos minerais que enriquecem quimicamente esses sedimentos encontra-se numa condição de biodisponibilidade para os organismos aquáticos, conforme argumentado por Sonzogni et al. (1982).

A quantidade de sedimentos suspensos na enxurrada da chuva $\mathrm{C} 1$ foi influenciada pelo tipo de adubação 
Quadro 4. Contraste de médias das concentrações de sedimentos totais e sedimentos suspensos na enxurrada nas três chuvas simuladas (C1, C2 e C3), nos tratamentos com adubação orgânica (dejeto líquido de suíno - DLS), adubação mineral (NPK) e sem adubação ou testemunha (T)

\begin{tabular}{|c|c|c|c|c|c|}
\hline \multirow{2}{*}{ Chuva } & \multicolumn{3}{|c|}{ Tratamento } & \multicolumn{2}{|c|}{ Contraste } \\
\hline & DLS & NPK & $\mathbf{T}$ & T vs DLS, NPK & DLS vs NPK \\
\hline \multicolumn{6}{|c|}{ Sedimentos totais na enxurrada $\left(\mathrm{g} \mathrm{L}^{-1}\right)$} \\
\hline $\mathrm{C} 1\left(70 \mathrm{~mm} \mathrm{~h}^{-1} ; 23 \mathrm{~mm}\right)$ & $2,804 \pm 0,36$ & $2,666 \pm 0,28$ & $3,266 \pm 0,38$ & 0,2777 & 0,6771 \\
\hline $\mathrm{C} 2\left(60 \mathrm{~mm} \mathrm{~h}^{-1} ; 20 \mathrm{~mm}\right)$ & $2,354 \pm 0,22$ & $2,313 \pm 0,13$ & $2,785 \pm 0,13$ & 0,0631 & 0,8065 \\
\hline $\mathrm{C} 3\left(120 \mathrm{~mm} \mathrm{~h}^{-1} ; 40 \mathrm{~mm}\right)$ & $6,109 \pm 0,29$ & $6,178 \pm 0,34$ & $4,667 \pm 0,07$ & 0,0029 & 0,5269 \\
\hline \multicolumn{6}{|l|}{ Contraste } \\
\hline $\mathrm{C} 1$ vs $\mathrm{C} 2, \mathrm{C} 3$ & 0,0092 & 0,0006 & 0,1253 & & \\
\hline $\mathrm{C} 2$ vs $\mathrm{C} 3$ & $<0,0001$ & $<0,0001$ & 0,0003 & & \\
\hline \multicolumn{6}{|c|}{ Sedimentos suspensos na enxurrada $\left(\mathrm{g} \mathrm{L}^{-1}\right)$} \\
\hline $\mathrm{C} 1\left(70 \mathrm{~mm} \mathrm{~h}^{-1} ; 23 \mathrm{~mm}\right)$ & $1,009 \pm 0,06$ & $1,026 \pm 0,06$ & $0,949 \pm 0,04$ & 0,2676 & 0,9205 \\
\hline $\mathrm{C} 2\left(60 \mathrm{~mm} \mathrm{~h}^{-1} ; 20 \mathrm{~mm}\right)$ & nd & nd & nd & & \\
\hline $\mathrm{C} 3\left(120 \mathrm{~mm} \mathrm{~h}^{-1} ; 40 \mathrm{~mm}\right)$ & $0,830 \pm 0,03$ & $1,052 \pm 0,05$ & $1,039 \pm 0,06$ & 0,0906 & 0,0122 \\
\hline \multicolumn{6}{|l|}{ Contraste } \\
\hline $\mathrm{C} 2$ vs $\mathrm{C} 3$ & 0,0695 & 0,7543 & 0,1741 & & \\
\hline
\end{tabular}

$\operatorname{Pr}>\mathrm{F}=\mathrm{p}$-valor da estatística $\mathrm{F}$ para contrastes ortogonais; nd = não determinado.

(Quadro 3). Os valores dessa variável seguiram a mesma tendência da quantidade de sedimentos totais na enxurrada, também podendo ser explicados pelo volume de enxurrada gerado em cada chuva, em cada tratamento. Isso é confirmado pelo fato de que a concentração de sedimentos suspensos na enxurrada não foi influenciada pelos tratamentos estudados (Quadro 4).

A quantidade de sedimentos suspensos na enxurrada da chuva C3 foi maior do que a verificada na enxurrada da chuva $\mathrm{C} 1$, nos três tratamentos estudados (Quadro 4). A perda de sedimentos totais na chuva C3 foi entre 2,4 e 4,5 vezes maior do que na chuva $\mathrm{C} 1$, enquanto a perda de sedimentos suspensos na enxurrada da chuva C3 foi entre 5,9 e 9,7 vezes maior do que a da chuva $\mathrm{C} 1$. Isso significa que a enxurrada da chuva C3 transportou maior quantidade de sedimentos de textura mais grosseira do que a enxurrada da chuva $\mathrm{C} 1$, inferido pelo fato de que a concentração de sedimentos suspensos na enxurrada não teve influência das chuvas simuladas. Esse comportamento pode ser explicado como segue. Os sedimentos de textura mais fina foram, em sua grande parte, transportados pelas enxurradas ocasionadas pelas duas primeiras chuvas principais (C1 e C2), em razão da sua maior disponibilidade nesse momento, e também devido à seletividade do processo erosivo, já que essas chuvas foram de menor intensidade. A chuva mais intensa (C3) produziu enxurrada com maior energia de transporte do que as demais e, portanto, transportou sedimentos maiores e mais densos. Ademais, o maior teor de água no solo proporcionado pelas duas primeiras chuvas (C1 e C2) diminuiu a resistência do solo à desagregação e, por essa razão, favoreceu a remoção de partículas do solo de maior tamanho na chuva C3.

A quantidade total de sedimentos suspensos na enxurrada removida das parcelas deste estudo pode ser considerada pequena em termos absolutos. No entanto, se tais sedimentos fossem depositados em mananciais de água, eles poderiam constituir problema sério, tendo em vista que, provavelmente, eles ocasionariam turbidez da água, em conseqüência do movimento errático que eles apresentam em meio líquido (Tundisi, 2001). Isso contribuiria para a degradação do ambiente aquático e, conseqüentemente, afetaria os seres vivos que dependem da qualidade do alimento orgânico sintetizado pela atividade de algas e de outros seres clorofilados.

A demanda química de oxigênio (DQO) da enxurrada com os sedimentos totais, no tratamento DLS, foi superior à dos demais tratamentos (Quadro 5), evidenciando a capacidade do dejeto líquido de suíno de contaminar a enxurrada com matéria orgânica. Isso indica, portanto, o elevado potencial de eutrofização das águas desse material, conforme argumentado por Scherer et al. (1996), uma vez que a matéria orgânica no meio aquático proporciona a proliferação de algas (Tundisi, 2001) e aumenta a disponibilidade de elementos tóxicos, como o nitrito (Kubitza, 2003). Segundo os critérios adotados pela UNESCO (1992), valores de DQO entre 20 e $200 \mathrm{mg} \mathrm{L}^{-1}$ de $\mathrm{O}_{2}$ indicam que a água está contaminada por compostos orgânicos. Pode-se inferir, disso, que em todos os tratamentos estudados as enxurradas apresentariam alto potencial de contaminação de mananciais de água superficial. 
Os tratamentos estudados influenciaram a condutividade elétrica (CE) da enxurrada com sedimentos totais em todas as chuvas simuladas (Quadro 5). Os valores mais elevados de CE foram observados no tratamento com dejeto líquido de suíno (DLS), sendo eles, aproximadamente, duas vezes maiores do que os observados na adubação mineral (NPK) e em torno de três vezes mais elevado do que no tratamento testemunha (T). Esses resultados podem ter sido influenciados pelo sódio $(\mathrm{Na})$ presente no dejeto líquido de suíno, em decorrência de a ração fornecida aos animais conter $\mathrm{NaCl}$, concordando com o observado por Eghball \& Gilley (1999), os quais, avaliando a CE em diferentes sistemas de manejo do solo, com diferentes tipos de adubação, encontraram maior valor no solo que recebeu dejeto líquido de bovinos, comparado com o solo que recebeu adubação mineral. Pode-se também considerar que os resultados observados no tratamento sem adubação (T) foram expressivos (próximos dos valores do tratamento NPK), refletindo o acúmulo de nutrientes na superfície do solo sob semeadura direta, em relação ao método convencional de preparo do solo, conforme também constatado por Eghball \& Gilley (1999). As chuvas simuladas aplicadas, entretanto, não influenciaram a CE da enxurrada (Quadro 5).

Os valores da CE da enxurrada com os sedimentos suspensos foram semelhantes aos da enxurrada com sedimentos totais, indicando que os elementos químicos presentes nesta última mantiveram-se na enxurrada com sedimentos suspensos. Com base nesses resultados e no fato de que a enxurrada normalmente contém sedimentos suspensos, enriquecidos de nutrientes (em razão das suas propriedades coloidais), pode-se inferir que as enxurradas provindas de lavouras conduzidas sob a técnica de semeadura direta, em especial, podem promover alterações químicas e biológicas nos mananciais de água localizados fora do local de origem da erosão. Esse efeito pode ser particularmente danoso no caso do transporte de $\mathrm{P}$, uma vez que este elemento é o principal causador da eutrofização das águas de superfície.

Os tratamentos estudados também influenciaram o pH da enxurrada com sedimentos totais, tendo o dejeto líquido de suíno (DLS) proporcionado enxurrada com tendência para a alcalinidade ( $\mathrm{pH}$ em torno de $7,4)$, enquanto os demais tratamentos proporcionaram

Quadro 5. Contraste de médias da demanda química de $\mathrm{O}_{2}$ (DQO) e da condutividade elétrica (CE) da enxurrada com os sedimentos totais e da condutividade elétrica (CE) da enxurrada com os sedimentos suspensos, nas três chuvas simuladas (C1, C2 e C3), nos tratamentos com adubação orgânica (dejeto líquido de suíno - DLS), adubação mineral (NPK) e sem adubação ou testemunha (T)

\begin{tabular}{|c|c|c|c|c|c|}
\hline \multirow{2}{*}{ Chuva } & \multicolumn{3}{|c|}{ Tratamento } & \multicolumn{2}{|c|}{ Contraste } \\
\hline & DLS & NPK & $\mathbf{T}$ & T vs DLS, NPK & DLS vs NPK \\
\hline & \multicolumn{3}{|c|}{ DQO $\left(\mathrm{O}_{2} \mathrm{~L}^{-1}\right)$ da enxurrada com sedimentos totais } & \multicolumn{2}{|c|}{$\operatorname{Pr}>\mathrm{F}$} \\
\hline $\mathrm{C} 1\left(70 \mathrm{~mm} \mathrm{~h}^{-1} ; 23 \mathrm{~mm}\right)$ & $317 \pm 101$ & $84 \pm 17$ & $84 \pm 12$ & 0,1430 & 0,0220 \\
\hline $\mathrm{C} 2\left(60 \mathrm{~mm} \mathrm{~h}^{-1} ; 20 \mathrm{~mm}\right)$ & nd & nd & $\mathrm{Nd}$ & & \\
\hline C3 $\left(120 \mathrm{~mm} \mathrm{~h}^{-1} ; 40 \mathrm{~mm}\right)$ & $259 \pm 45$ & $120 \pm 15$ & $149 \pm 21$ & 0,3010 & 0,0100 \\
\hline Contraste & \multicolumn{3}{|c|}{$\operatorname{Pr}>\mathrm{F}$} & & \\
\hline \multirow[t]{2}{*}{$\mathrm{C} 2$ vs $\mathrm{C} 3$} & 0,6300 & 0,1700 & 0,0400 & & \\
\hline & \multicolumn{3}{|c|}{$\mathrm{CE}(\mu \mathrm{S} / \mathrm{cm})$ da enxurrada com sedimentos totais } & \multicolumn{2}{|c|}{$\operatorname{Pr}>\mathrm{F}$} \\
\hline $\mathrm{C} 1\left(70 \mathrm{~mm} \mathrm{~h}^{-1} ; 23 \mathrm{~mm}\right)$ & $83,8 \pm 11,6$ & $43,7 \pm 9,2$ & $29,9 \pm 1,1$ & 0,0063 & 0,0360 \\
\hline $\mathrm{C} 2\left(60 \mathrm{~mm} \mathrm{~h}^{-1} ; 20 \mathrm{~mm}\right)$ & $73,3 \pm 9,4$ & $35,0 \pm 4,7$ & $26,3 \pm 1,7$ & 0,0009 & 0,0123 \\
\hline $\mathrm{C} 3\left(120 \mathrm{~mm} \mathrm{~h}^{-1} ; 40 \mathrm{~mm}\right)$ & $87,3 \pm 7,3$ & $48,2 \pm 4,0$ & $28,8 \pm 2,0$ & 0,0004 & $<0,0001$ \\
\hline Contraste & \multicolumn{3}{|c|}{$\operatorname{Pr}>\mathrm{F}$} & & \\
\hline $\mathrm{C} 1$ vs $\mathrm{C} 2, \mathrm{C} 3$ & 0,2400 & 0,4700 & 0,1800 & & \\
\hline $\mathrm{C} 2$ vs $\mathrm{C} 3$ & 0,4600 & 0,1300 & 0,2500 & & \\
\hline \multicolumn{6}{|c|}{$\mathrm{CE}(\mu \mathrm{S} / \mathrm{cm})$ da enxurrada com sedimentos suspensos } \\
\hline $\mathrm{C} 1\left(70 \mathrm{~mm} \mathrm{~h}^{-1} ; 23 \mathrm{~mm}\right)$ & $82,7 \pm 11,5$ & $43,3 \pm 9,1$ & $29,5 \pm 1,1$ & 0,0100 & 0,0090 \\
\hline $\mathrm{C} 2\left(60 \mathrm{~mm} \mathrm{~h}^{-1} ; 20 \mathrm{~mm}\right)$ & $\mathrm{Nd}$ & $\mathrm{Nd}$ & $\mathrm{Nd}$ & & \\
\hline C3 $\left(120 \mathrm{~mm} \mathrm{~h}^{-1} ; 40 \mathrm{~mm}\right)$ & $86,2 \pm 7,3$ & $47,54 \pm 3,9$ & $28,4 \pm 2,0$ & 0,0001 & 0,0003 \\
\hline Contraste & \multicolumn{3}{|c|}{$\operatorname{Pr}>\mathrm{F}$} & & \\
\hline $\mathrm{C} 2$ vs $\mathrm{C} 3$ & 0,3100 & 0,6900 & 0,6600 & & \\
\hline
\end{tabular}

$\operatorname{Pr}>\mathrm{F}=\mathrm{p}$-valor da estatística $\mathrm{F}$ para contrastes ortogonais; nd= não determinado. 
enxurrada com tendência para a neutralidade ( $\mathrm{pH}$ em torno de 7,0 - Quadro 6). Os resultados encontrados podem ter sido influenciados, em parte, pelo $\mathrm{pH}$ do dejeto líquido de suíno, visto que Bitzer \& Sims (1988) reportam que dejetos de animais podem ter $\mathrm{pH}$ superior a 8,0 e Scherer et al. (1995) constataram pH de até 8,2 em dejeto de suíno. Considerando a influência do $\mathrm{pH}$ da água sobre os organismos aquáticos, a enxurrada do tratamento DLS mostrouse mais prejudicial do que as dos demais tratamentos, no que se refere ao comprometimento dos ambientes aquáticos. Conforme relatado por Kubitza (2003), o aumento da alcalinidade da água aumenta a concentração da forma não-ionizada da amônia $\left(\mathrm{NH}_{3}\right)$, elemento especialmente tóxico para peixes. Ainda conforme o referido autor, a percentagem de tal elemento na água triplica quando o $\mathrm{pH}$ passa de 7,0 para 7,5 .

Os resultados obtidos neste trabalho, no que diz respeito às perdas de solo e água, estão de acordo com os verificados em outros trabalhos, também realizados em áreas cultivadas sob a técnica de semeadura direta, conforme já mencionado. Por outro lado, os valores de condutividade elétrica (CE) da enxurrada com os sedimentos totais e com os sedimentos suspensos foram elevados em todos os tratamentos estudados $\mathrm{e}$ são indicativos da carga de sólidos em suspensão, principalmente de elementos minerais, tendo em vista que a $\mathrm{CE}$ tem relação direta com a presença destes na enxurrada. Esses resultados, portanto, evidenciam a necessidade de se conter a enxurrada na lavoura, mesmo sob a técnica de semeadura direta. Essa necessidade fica ainda mais evidente no caso dos sedimentos finos (suspensos na enxurrada), pois estes dificilmente são retidos nos resíduos vegetais existentes na superfície do solo (característica notável da técnica de semeadura direta). A contenção do escoamento superficial por meio de terraceamento bem dimensionado, por exemplo, permite que o efeito depurador do solo diminua a carga iônica da enxurrada, conforme argumentado por Bertol (2005), já que a água tenderá a se infiltrar no solo na região dos canais dos terraços. Ademais, os terraços controlam a dinâmica da enxurrada no tocante às perdas de solo e água. Portanto, o controle da enxurrada em semeadura direta irá repercutir positivamente nos aspectos econômico e ambiental, uma vez que, em assim fazendo, serão evitadas tanto a perda de nutrientes das lavouras via enxurrada quanto a conseqüente eutrofização das águas.

\section{CONCLUSÕES}

1. O solo adubado com dejeto líquido de suíno causou maior enxurrada do que o adubado com adubo mineral nas duas primeiras chuvas simuladas, sem diferenças, contudo, na terceira chuva.

2. Tendo em vista o exposto anteriormente, as perdas de solo e água nas duas primeiras chuvas foram maiores no solo adubado com dejeto líquido de suíno do que no adubado com adubo mineral.

3. O dejeto líquido de suíno aplicado no solo proporcionou maiores demanda química de oxigênio e condutividade elétrica na enxurrada do que quando o solo recebeu adubo mineral.

4. As perdas de sedimento e água, a demanda química de oxigênio, a condutividade elétrica e o pH da enxurrada observados neste estudo evidenciam a necessidade de se controlar a enxurrada mesmo em áreas cultivadas sob a técnica de semeadura direta, o que pode ser conseguido por meio da implantação de estruturas mecânicas para sua contenção.

Quadro 6. Contraste de médias do pH da enxurrada com os sedimentos totais nas três chuvas simuladas (C1, C2 e C3), nos tratamentos com adubação orgânica (dejeto líquido de suíno - DLS), adubação mineral (NPK) e sem adubação ou testemunha (T)

\begin{tabular}{|c|c|c|c|c|c|}
\hline \multirow{2}{*}{ Chuva } & \multicolumn{3}{|c|}{ Tratamento } & \multicolumn{2}{|c|}{ Contraste } \\
\hline & DSL & NPK & $\mathbf{T}$ & T vs DSL, NPK & DSL vs NPK \\
\hline \multicolumn{6}{|c|}{$\mathrm{pH}$ da enxurrada com os sedimentos totais } \\
\hline $\mathrm{C} 1\left(70 \mathrm{~mm} \mathrm{~h}^{-1} ; 23 \mathrm{~mm}\right)$ & $7,4 \pm 0,08$ & $6,8 \pm 0,27$ & $7,2 \pm 0,11$ & 0,845 & 0,039 \\
\hline $\mathrm{C} 2\left(60 \mathrm{~mm} \mathrm{~h}^{-1} ; 20 \mathrm{~mm}\right)$ & $7,4 \pm 0,07$ & $7,0 \pm 0,13$ & $7,1 \pm 0,08$ & 0,413 & 0,023 \\
\hline $\mathrm{C} 3\left(120 \mathrm{~mm} \mathrm{~h}^{-1} ; 40 \mathrm{~mm}\right)$ & $7,4 \pm 0,10$ & $7,1 \pm 0,1$ & $6,9 \pm 0,08$ & 0,010 & 0,018 \\
\hline \multicolumn{6}{|l|}{ Contraste } \\
\hline Ch1 vs Ch2, Ch3 & 0,943 & 0,329 & 0,205 & & \\
\hline Ch 2 vs $\mathrm{Ch} 3$ & 0,838 & 0,822 & 0,176 & & \\
\hline
\end{tabular}

$\operatorname{Pr}>\mathrm{F}=$ p-valor da estatística $\mathrm{F}$ para contrastes ortogonais; nd = não determinado. 


\section{LITERATURA CITADA}

BERTOL, O.J.; AMADO, T.J.C.; SCHLOSSER, J.F. \& REINERT, D.J. Desempenho de mecanismos sulcadores de semeadura sob condições de preparo reduzido do solo, R. Bras. Ci. Solo, 21:257-262, 1997.

BERTOL, I.; GUADAGNIN, J.C.; CASSOL, P.C.; AMARAL, A.J. \& BARBOSA, F.T. Perdas de fósforo e potássio por erosão hídrica em um Inceptisol sob chuva natural. R. Bras. Ci. Solo, 28:485-494, 2004.

BERTOL, O.J. Contaminação da água de escoamento superficial e da água percolada pelo efeito de adubação mineral e adubação orgânica em sistema de semeadura direta. Curitiba, Universidade Federal do Paraná, 2005. 208p. (Tese de Doutorado)

BERTOL, I.; ENGEL, F.; MAFRA, A.L.; BERTOL, O.J. \& RITTER, S. Phosphorus, potassium and organic carbon concentrations in runoff under different soil tillage systems during soybean growth. Soil \& Till. Res., 2007. (Aprovado)

BITZER, C.C. \& SIMS, J.T. Estimating the availability of nitrogen in poultry manure through laboratory and field studies. J. Environ. Qual., 17:47-54, 1988.

BRASIL. Ministério da Agricultura. Secretaría Nacional de Planejamento Agrícola. Aptidão Agrícola das Terras do Paraná. Brasília, 1981. 140p.

COGO, N.P. Effect of residue cover, tillage induced-roughness, and slope lenght on erosion and related parameters. West Lafayette, Purdue University, 1981. 346p. (Tese de Doutorado)

COGO, N.P.; LEVIEN, R. \& SCHWARZ, R.A. Perda de solo e água por erosão hídrica influenciadas por métodos de preparo, classes de declive e níveis de fertilidade do solo. R. Bras. Ci. Solo, 27:743-753, 2003.

EGHBALL, B. \& GILLEY, E. Phosphorus and nitrogen in runoff following beef cattle manure or compost application. J. Environ. Qual., 28:1201-1210, 1999.

EMPRESA BRASILEIRA DE PESQUISA AGROPECUÁRIA EMBRAPA. Manual de métodos de análise de solo. 2.ed. Rio de Janeiro, 1997. 212p. (Documentos, 1)

EMPRESA BRASILEIRA DE PESQUISA AGROPECUÁRIA EMBRAPA. Sistema brasileiro de classificação de solos. Brasília, 1999. 412p.

FOSTER, G.R. Modelling the erosion process. In: HAAN, C.T.; JOHNSON, H.D. \& BRAKENSIEK, D.L., eds. Hydrologic modeling of small watersheds. St. Joseph, ASAE, 1982. p.297-380.

HAYNES, R.J. \& SWIFT, R.S. Stability of soil aggregates in relation to organic constituents and soil water content. J. Soil Sci., 41:73-83, 1990.

KOSKI-VÄHÄLÄ, J. \& HARTIKAINEN, H. Assessment of the risk of phosphorus loading due to resuspended sediment. J. Environ. Qual., 30:960-966, 2001.
KUBITZA, F. Qualidade da água no cultivo de peixes e camarões. Jundiaí, 2003. 229p.

McDOWELL, L.L. \& SHARPLEY, A.N. Phosphorus losses in subsurface flow before and after manure application to intensively farmed land. Sci. Total Environ., 278:113-125, 2001.

McKEAGUE, J.A. Manual on soil sampling and methods of analysis. Ottawa, Canadian. Society of Soil Science., 1978. 212 p.

MEHRA, O.P. \& JACKSON, M.L. Iron oxide removal from soils and clay by a dithionite-citrate system buffered with sodium bicarbonate. Clay Miner., 7:317-327, 1960.

MELO, V.F.; SING, B.; SCHAEFER, C.E.G.R.; NOVAIS, R.F. \& FONTES, M.P.F. Chemical and mineralogical properties of kaolinite-rich Brazilian soils. Soli Sci. Soc. Am. J., 65:1324-1333, 2001.

MEYER, L.D.; FOSTER, G.R. \& RÖMKENS, M.J.M. Source of soil eroded by water from upland slopes. In: Present and prospective technology for predicting sediment yields and sources. Washington, USDA-Agricultural Research, 1975. p.177-189.

PAVAN, M.A.; BLOCH, M.F.; ZEMPULSKI, H.C.; MIYAZAWA, M. \& ZOCOLER, D.C. Manual de análise química de solo e controle de qualidade. Londrina, IAPAR, 1992, 39p. (Circular, 76)

REICHERT, J.M. \& CABEDA, M.S.V. Salpico de partículas e selamento superficial em solos do Rio Grande do Sul. R. Bras. Ci. Solo, 16:389-396, 1992.

SCHERER, E.E.; BALDISSERA, I.T. \& XAVIER DIAS, L.F. Potencial fertilizante do esterco líquido de suínos da região oeste catarinense. Agropec. Catarinense, 8:35-35, 1995.

SCHERER, E.E.; AITA, C. \& BALDISSERA, I.T. Avaliação da qualidade do esterco líquido de suíno da região oeste catarinense para fins de utilização como fertilizante. Florianópolis, EPAGRI, 1996. 46p. (Boletim Técnico, 79)

SCHICK, J.; BERTOL, I.; BALBINOT JUNIOR, A.A. \& BATISTELA, O. Erosão hídrica em Cambissolo Húmico alumínico submetido a diferentes sistemas de preparo e cultivo do solo: II. Perdas de nutrientes e carbono orgânico. R. Bras. Ci. Solo, 24:437-447, 2000.

SHARPLEY, A.N.; MCDOWELL R.W. \& KLEINMAN, P.T.A. Phosphorus loss from land to water: integrating agricultural and environmental management. Plant Soil, 237:287-307, 2001.

SONZOGNI, W.C.; CHAPRA, S.C.; ARMSTRONG, D.E. \& LOGAN, T.J. Bioavailability of phosphorus inputs to tlakes. J. Environ. Qual., 11:555-562, 1982.

STEEL, R.G.D. \& TORRIE, J.H. Principles and procedures of statistics: a biometrical approach. 2.ed. New York, 1980. 631 .

SWANSON, N.P. Suggestions for the use of the rotatingboom field plot rainfall simulator to obtain data for application of the soil loss equation. Paraná, FAO, University of Nebraska, 1965. 58p. (Relatório de Consultoria) 
TUNDISI, J.G. Biomanipulação para o gerenciamento de lagos e represas. In: Diretrizes para o gerenciamento de lagos.2.ed. São Carlos, ILEC, 2001. v.7. p.33-51.
UNESCO/WHO \& UNEP. Water quality assessment. London, 1992. 585p. 